\title{
Combination of AgNPs and Domiphen is Antimicrobial Against Biofilms of Common Pathogens
}

\author{
Longhao $\mathrm{Hu}^{1}$,* \\ Xi Yang ${ }^{2,3, *}$ \\ Jing Yin' \\ Xuan Rong' \\ Xinlei Huang' \\ Peiquan $\mathrm{Yu}^{3}$ \\ Zhiqiang $\mathrm{He}^{1}$ \\ Yi Liu (D) ${ }^{1-3}$
}

'Department of Biophysics, School of Life Sciences, Xuzhou Medical University, Xuzhou, Jiangsu, 221004, People's Republic of China; ${ }^{2}$ School of Pharmacy, Xuzhou Medical University, Xuzhou, Jiangsu, 22 1004, People's Republic of China; ${ }^{3}$ Jiangsu Key Laboratory of New Drug Research and Clinical Pharmacy, Xuzhou Medical University, Xuzhou, Jiangsu, 221004, People's Republic of China

*These authors contributed equally to this work
Purpose: The aim was to evaluate the antimicrobial potential of AgNPs synthesized with Artemisia argyi leaf extract and investigate the antimicrobial synergistic effects of AgNPs combined with domiphen and provide an efficient and broad-spectrum combination drug strategy.

Methods: AgNPs synthesized with Artemisia argyi leaf extract were studied using UV-vis spectroscopy, FTIR spectroscopy and particle size analysis. Then, Artemisia argyi leaf extract-synthesized AgNPs and domiphen were tested against Acinetobacter baumannii (ATCC 19606), Staphylococcus aureus (ATCC 6538), Escherichia coli (8099) and Candida albicans (ATCC 10231), respectively. Then, we explore synergistic antimicrobial effect and synergistic anti-biofilm effect through combined drug susceptibility test and combined drug minimum biofilm eradication concentration $\left(\mathrm{MBEC}_{50}\right)$ test.

Results: Characteristic absorption bands of AgNPs were found near $430 \mathrm{~nm}$ in the UV-vis spectrum. Particle size analysis results revealed that the average particle size of Artemisia argyi leaf extract-synthesized AgNPs was $77.6 \mathrm{~nm}$. Artemisia argyi leaf extract-synthesized AgNPs showed high antimicrobial activity against the above four strains. Minimum inhibitory concentration (MIC) of Artemisia argyi leaf extract-synthesized AgNPs against strains was $1 \mu \mathrm{g} /$ $\mathrm{mL}$ for Acinetobacter baumannii, $2 \mu \mathrm{g} / \mathrm{mL}$ for Staphylococcus aureus, Escherichia coli and Candida albicans. $\mathrm{MBEC}_{50}$ of Artemisia argyi leaf extract-synthesized AgNPs against strains was $2 \mu \mathrm{g} / \mathrm{mL}$ for Acinetobacter baumannii, $4 \mu \mathrm{g} / \mathrm{mL}$ for Staphylococcus aureus, $1 / 2 \mu \mathrm{g} / \mathrm{mL}$ for Escherichia coli and $2 \mu \mathrm{g} / \mathrm{mL}$ for Candida albicans. The combination of Artemisia argyi leaf extract-synthesized AgNPs and domiphen has synergistic antimicrobial effect and synergistic anti-biofilm effect. Fractional inhibitory concentration (FIC) was $\leq 0.5$.

Conclusion: Artemisia argyi leaf extract-synthesized AgNPs had antimicrobial activity against the above four strains. The combination of Artemisia argyi leaf extract-synthesized AgNPs and domiphen has synergistic antimicrobial effects to reduce the dosage of each antimicrobial drugs. Artemisia argyi leaf extract-synthesized AgNPs and domiphen have synergistic anti-biofilm effects.

Keywords: AgNPs, domiphen, synergy, pathogenic biofilm, combination medication

\section{Introduction}

Pathogens can invade the human body, especially the respiratory system and brain, resulting in various diseases such as tuberculosis, acute lower respiratory tract infection, and bacterial meningitis. ${ }^{1,2}$ Due to the constant changes of pathogens, pathogenic diseases are difficult to treat. The misuse or overuse of antimicrobial agents are the main drivers in the development of drug-resistant pathogens, which
Correspondence: Yi Liu

Department of Biophysics, School of Life Sciences, Xuzhou Medical University,

Xuzhou, Jiangsu, 221004, People's

Republic of China

$\mathrm{Tel} / \mathrm{Fax}+86-516-83262084$

Email cbpeliuyinew@I63.com 
brings out direct or potential threats to public health. ${ }^{3-5}$ Pathogenic biofilms are complex, mono- or poly-microbial communities adhering to biotic or abiotic surfaces. Characteristically, gradients of nutrients and oxygen exist from the top to the bottom of biofilms and these gradients are associated with decreased bacterial metabolic activity and increased doubling times of the bacterial cells. It is these more or less dormant cells that are responsible for some of the tolerance to antibiotics. Conventional resistance mechanisms such as chromosomal $\beta$-lactamase, upregulated efflux pumps and mutations in antibiotic target molecules in bacteria also contribute to the presence of biofilms. ${ }^{6}$ Furthermore, the formation of pathogenic biofilms is positively correlated with microbial resistance. ${ }^{7}$

The intricate clinical conditions have led to the fact that the use of antimicrobials alone can no longer meet the needs of treatment. Accordingly, these multiple infections or highly resistant pathogens are usually treated with combined drugs in clinical practice. ${ }^{8-10}$ However, irrational use of antimicrobial drugs in combination may reduce the efficacy. Therefore, it is necessary to analyze the potential mechanism underlying the formation of drugresistant pathogens, so as to provide guidance for screening out antimicrobial drugs with potential synergistic effects.

Metal nanoparticles are a new type of antimicrobial agent, which are mostly used for in vitro sterilization, surface disinfection, and purification of daily drinking water. Recently, as the most commonly used metal nanoparticles, AgNPs have drawn increasing attention and their physical and chemical properties, antimicrobial activities, and toxicity to mammalian cells have been characterized. ${ }^{11-13}$ However, the molecular mechanisms of their bacteriostasis and sterilization have not been clearly described. ${ }^{14,15}$ Notably, the large-amount use of AgNPs may cause sedimentation and aggregation, which then reduces their antimicrobials effects. In contrast, as a cationic surfactant, domiphen exerts broad-spectrum antimicrobials effects, inhibit microbial growth at a low concentration, ${ }^{16}$ and fully disperses AgNPs. The combined use of both drugs may produce synergistic effects, and act as a new strategy for the selection of antimicrobial drugs and clinical treatment.

Generally, different physical and chemical methods are employed for the synthesis of AgNPs, ${ }^{17}$ such as chemical reduction, ${ }^{18}$ photochemical reduction, ${ }^{19}$ electroirradiation, $^{20}$ ultraviolet (UV) irradiation ${ }^{21}$ and lasermediated synthesis. ${ }^{22}$ However, most techniques used for the synthesis of AgNPs are expensive or have adversely affect the environment and biological systems. ${ }^{23}$ Green synthesis of AgNPs using extracts of plants as reducing and stabilizing agents offers comparatively safer and ecofriendly and biological-mediated approach. Artemisia argyi leaf as traditional Chinese medicine have various biological activities, including neuroprotective, ${ }^{24,25}$ anticancer, ${ }^{26}$ antiplasmodial ${ }^{27,28}$ and antioxidant. ${ }^{29-31}$ The strong antioxidant activity and the biosynthetic potential of this species for phenolics and flavonoids ${ }^{32-35}$ may be considered as potential factors for reducing $\mathrm{Ag}^{+}$to AgNPs.

In the current study, the present work was aimed to evaluate the antimicrobial potential of Artemisia argyi leaf extract and silver nitrate to synthesize biologically stable silver nanoparticles. We intend to investigate the antimicrobial synergistic effects of AgNPs combined with domiphen and explore related inhibitory mechanisms. The results will provide theoretical evidence for the prevention and treatment of many pathogens, providing guidance for rational design of products with high antimicrobial performance and improving the safety of antimicrobial agents. ${ }^{2}$

\section{Materials and Methods}

\section{Reagents}

Acinetobacter baumannii (ATCC 19606), Staphylococcus aureus (ATCC 6538), Escherichia coli (8099) and Candida albicans (ATCC 10231) were purchased from Shanghai Luwei Technology Co., Ltd (China). $\mathrm{AgNO}_{3}$ (99.8\%) and domiphen (97\%) were purchased from Sinopharm Chemical Reagent Co., Ltd (China) and Shanghai Yien Chemical Technology Co., Ltd (China), respectively. Artemisia argyi leaf extract was purchased from Xi'an Runxue Bio-technology Co., Ltd (China). Mueller-Hinton Broth (MHB) and Tryptose Soya Agar (TSA) were purchased Qingdao Hope Bio-Technology Co., Ltd (China). Crystal violet staining solution was purchased from Jiangsu KEYGEN Bio-Technology Co., Ltd (China). Mc's turbidimetric tubes were purchased from Jiangsu KEYGEN Bio-Technology Co., Ltd (China).

\section{Preparation of AgNPs}

Briefly, $8.5 \mathrm{mg}$ of silver nitrate and $10 \mathrm{mg}$ of Artemisia argyi leaf extract were weighed using an analytical balance of $1 / 10,000$, which were then dissolved in $5.0 \mathrm{~mL}$ distilled water, and soaked in boiling water at $100^{\circ} \mathrm{C}$ for 40 min to prepare $1000 \mu \mathrm{g} / \mathrm{mL} \mathrm{AgNPs} \mathrm{solution.} \mathrm{The} \mathrm{resultant}$ product was dried away from light for storage. 


\section{Characterization of AgNPs}

UV-Visible Spectroscopic Characterization of AgNPs

The formation of AgNPs was observed under an UVvisible spectrophotometer (UV 1601, Shimadzu) in the wavelength range of $250-850 \mathrm{~nm}$.

\section{Fourier Transform Infrared Spectroscopic Studies}

Fourier transform infrared (FT-IR) spectroscopic studies were performed using spectrum RX 1 instrument. The obtained samples were mixed with $\mathrm{KBr}$, made into pellets, and analyzed to determine the presence of functional groups in the phytoconstituents on the extract of Artemisia argyi leaf and the synthesized AgNPs. FT-IR spectra were scanned between $4000 \mathrm{~cm}^{-1}$ and $500 \mathrm{~cm}^{-1}$ at a resolution of $4 \mathrm{~cm}^{-1}$ in the transmittance mode.

\section{Particle Size Analysis}

DLS method was used to measure the particle size of AgNPs (NICOMP 380NLS, Santa Barbara, California, USA).

\section{Microbial Culture}

An appropriate amount of nutrient broth medium was added into a freeze-dried strain tube with a sterile pipette. A little strain suspension was dropped into a test tube containing 5.0 $10.0 \mathrm{~mL}$ nutrient broth medium, and incubated at $37^{\circ} \mathrm{C}$ for 18 $24 \mathrm{~h}$. The diluent of the third to fourteenth generation fresh culture of the nutrient agar slant $(3.0-5.0 \mathrm{~mL})$ was sucked into the oblique tube, and repeatedly pipetted and washed. Then, the washing solution was transferred to another sterile test tube, and mixed with a vortexer for $20 \mathrm{~s}$, or shook 80 times to make a uniform suspension. The microbial concentration was measured using Mc's turbidimetric method. The suspension of microbial propagules should be stored at $4^{\circ} \mathrm{C}$ for later use.

\section{The Inhibition Zone Assay}

First of all, $20 \mu \mathrm{L}$ of AgNPs or domiphen at different concentrations or sterile distilled water was added on sterile and dry filter paper. Then, placed on a clean sterile plate and dried in an incubator at $37^{\circ} \mathrm{C}$, or naturally dried at room temperature before use. Secondly, a sterile cotton swab was dipped into Acinetobacter baumannii suspension $\left(5 \times 10^{5}-5 \times 10^{6} \mathrm{CFU} / \mathrm{mL}\right)$ and evenly smeared on the surface of the nutrient agar medium plate for three times. The petri dish was covered and dried at room temperature for $5 \mathrm{~min}$. The sample piece was placed on the surface of the plate, which was covered and incubated at $37^{\circ} \mathrm{C}$ for $16-18 \mathrm{~h}$. The diameter of the antimicrobial ring (including the patch) was measured and a bacteriostatic ring with uniform growth was selected. Those reagents with a diameter of the antimicrobial ring greater than $7 \mathrm{~mm}$ were defined as having antimicrobial effects. ${ }^{36,37}$ The test procedures of AgNPs and domiphen against Staphylococcus aureus, Escherichia coli and Candida albicans are the same as those of Acinetobacter baumannii.

\section{Single Drug Susceptibility Test}

Briefly, AgNPs were separately added into seven sterile test tubes with dilution of MHB, to achieve the concentration of 32 , $16,8,4,2,1$, and $0 \mu \mathrm{g} / \mathrm{mL}$. Then, 0.5 McGill's turbidity of Acinetobacter baumannii (ATCC 19606) was prepared and diluted 100 times with sterile distilled water to achieve a concentration of about $1 \times 10^{6} \mathrm{CFU} / \mathrm{mL}$. Next, $50 \mu \mathrm{L}$ volume of bacterial suspension with an equal volume of AgNPs were mixed and incubated at $37^{\circ} \mathrm{C}$ for $18-24 \mathrm{~h}$. The turbidity of the solution in each test tube was measured. The minimum concentration of AgNPs without microbial growth (obviously clear) was the MIC of AgNPs acting on Acinetobacter baumannii. The test procedures of AgNPs and domiphen against Staphylococcus aureus, Escherichia coli and Candida albicans are the same as those of Acinetobacter baumannii.

\section{Combined Drug Susceptibility Test}

Briefly, 0.5 McGill's turbidity was prepared and diluted with sterile distilled water 100 times. AgNPs and domiphen were diluted with sterile MHB times from $8 \times$ MIC concentration. Six dilutions and $50 \mu \mathrm{L}$ of each were taken and arranged on a sterile 96 -well plate. To the plate, $100 \mu \mathrm{L}$ of microbial solution was added to make a final microbial inoculum amount of $5 \times 10^{5} \mathrm{CFU} / \mathrm{mL}$, and a final drug concentration of $2 \times$ MIC. The plate was then placed in an incubator at $37^{\circ} \mathrm{C}$ for $18-24 \mathrm{~h}$. The minimum drug concentration without microbial growth (obviously clear) was recorded as MIC' (the MIC' of AgNPs and domiphen may be different). The FIC calculation uses the following equation.

FIC $=\mathrm{MIC}^{\prime}(\mathrm{AgNPs}) / \mathrm{MIC}(\mathrm{AgNPs})+\mathrm{MIC}^{\prime}$ (Domiphen)/MIC (Domiphen).

\section{Minimum Bactericidal Concentration Test}

The concentration of the test drug was set according to the MIC of the pathogens. Briefly, AgNPs were separately added into eight sterile test tubes with dilution of MHB, to achieve the concentration gradient, before incubation at $37^{\circ} \mathrm{C}$ for $18-24 \mathrm{~h}$. Then, a sterile cotton swab was dipped into the solution and evenly smeared on a petri dish containing TSA medium, followed by being incubated at $37^{\circ} \mathrm{C}$ 
for 18-24 h. The number of pathogen colonies in the petri dishes was less than five, which was recorded as the minimum bactericidal concentration (MBC).

\section{Identification of the Ability of Each Pathogen to Form Pathogenic Biofilm}

0.5 McGill's turbidity of microbial solution was prepared and diluted 100 times with MHB (final concentration $10^{6}$ $\mathrm{CFU} / \mathrm{mL}$ ). Then, $100 \mu \mathrm{L}$ of the microbial dilution was added in a sterile 96-well plate, and incubated at $37^{\circ} \mathrm{C}$ for $1 \mathrm{~h}$ to form the pathogenic biofilm. Aspirate the sterilization solution and wash with PBS to remove planktonic bacteria. Add $100 \mu \mathrm{L}$ of MHB to each well and incubate in a $37{ }^{\circ} \mathrm{C}$ constant temperature incubator for $18 \mathrm{~h}$ to 24 h. Aspirate MHB and wash with PBS to remove residue. MHB, add $100 \mu \mathrm{L}$ methanol to fix for $15 \mathrm{~min}$. Aspirate the methanol, dry, and stain with crystal violet for $10 \mathrm{~min}$. Aspirate the crystal violet solution and wash with PBS 3 times. Measure the OD value with a microplate reader at $595 \mathrm{~nm}$. Taking 2 times the ODc value (ODc equal to the average OD value of the blank hole plus 3 times the standard deviation of the OD value) as the limit value, the strains are divided into: non-film-forming strains (ODc $\leq \mathrm{OD} \leq 2 \mathrm{ODc}$ ); weak strains with film-forming ability (2ODc $\leq \mathrm{OD} \leq 4 \mathrm{ODc})$; strains with medium filmforming ability (4ODc $\leq \mathrm{OD} \leq 6 \mathrm{ODc})$; strains with strong film-forming ability $(6 \mathrm{ODc} \leq \mathrm{OD}) .{ }^{38}$

\section{Pathogenic Biofilm Eradication Concentration Test and Combined Drug MBEC $_{50}$ Test}

Briefly, 0.5 McGill's turbidity of Acinetobacter baumannii was prepared and diluted 100 times with MHB (final concentration $10^{6} \mathrm{CFU} / \mathrm{mL}$ ). Then, $100 \mu \mathrm{L}$ of the diluted Acinetobacter baumannii was added in a sterile 96-well plate, and incubated at $37^{\circ} \mathrm{C}$ for $1 \mathrm{~h}$ to form the pathogenic biofilm. The sterilization solution was aspirated and washed with PBS to remove planktonic pathogens. AgNPs and domiphen were diluted with sterile MHB up to two times of the MIC, respectively, and six dilutions were taken. Next, $100 \mu \mathrm{L}$ of AgNPs or domiphen was arranged in a sterile 96-well plate, and incubated at $37^{\circ} \mathrm{C}$ for $24 \mathrm{~h}$. Then AgNPs solution was aspirated, and washed with PBS. After drying, $100 \mu \mathrm{L}$ of methanol was added to fix for $15 \mathrm{~min}$. After removal of methanol, the samples were covered with crystal violet solution for $10 \mathrm{~min}$. The OD value was measured by a microplate reader at $595 \mathrm{~nm}$.
Biofilm biomass $(\%$ of control $)=\left(1-\mathrm{OD}_{\text {test }} / \mathrm{OD}_{\text {control }}\right)$ $\times 100 \%$.

The minimum AgNPs concentration of biofilm biomass (\% of control) greater than $50 \%$ is $\mathrm{MBEC}_{50} \cdot{ }^{39,40}$

Using the micro checkerboard dilution method to test the combined drug $\mathrm{MBEC}_{50}$, the drug concentration and dosage have been modified as follows: AgNPs and domiphen were diluted with sterile MHB up to four times of the $\mathrm{MBEC}_{50}$ respectively, and six dilutions were taken. Next, $50 \mu \mathrm{L}$ of AgNPs and domiphen was arranged in a sterile 96-well plate, and incubated at $37^{\circ} \mathrm{C}$ for $24 \mathrm{~h}$. The minimum drug concentration of biofilm biomass ( $\%$ of control) greater than $50 \%$ is MBEC $_{50}$ (the MBEC' ${ }_{50}$ of AgNPs and domiphen may be different). The FIC calculation uses the following equation.

FIC $=$ MBEC' $_{50} \quad(\mathrm{AgNPs}) / \mathrm{MBEC}_{50} \quad(\mathrm{AgNPs})+$ MBEC' ${ }_{50}$ (Domiphen)/MBEC ${ }_{50}$ (Domiphen).

\section{Statistical Analysis}

All experimental results (expressed as mean $\pm \mathrm{SD}$ ) represent at least three discrete findings. The data were evaluated with one-way analysis of variance (ANOVA) followed by LSD post-hoc analysis. $P$ values $(<0.05)$ are considered as statistically significant.

\section{Results}

\section{AgNPs Characterization}

The absorption of AgNPs was near $440 \mathrm{~nm}$ in the UV-vis spectrum (Figure 1), due to surface plasmon resonance of AgNPs. No additional peaks were seen in the spectrum, which suggests that the biosynthesized products are silver alone.

Figure 2 shows the FT-IR spectra of the Artemisia argyi leaf extract-synthesized AgNPs. The strong band at $3437.15 \mathrm{~cm}^{-1}$ and $3439.14 \mathrm{~cm}^{-1}$ was attributed to the $\mathrm{O}-\mathrm{H}$ stretching band of alcohols and phenols. ${ }^{41}$ Absorption peaks located at $2927.94 \mathrm{~cm}^{-1}$ and $2,927.99 \mathrm{~cm}^{-1}$ corresponded to alkane $\mathrm{C}-\mathrm{H}$ stretching vibrational modes. ${ }^{42} \mathrm{~A}$ mediumintensity peak was observed at $1,639.49 \mathrm{~cm}^{-1}$ and $1636.62 \mathrm{~cm}^{-1}$, signifying the presence of carbonyl $(\mathrm{C}-\mathrm{O})$ stretching vibrations. ${ }^{43}$ The medium-intensity peak at $1,384.88 \mathrm{~cm}^{-1}$ and $1387.80 \mathrm{~cm}^{-1}$ was assigned to the $\mathrm{C}-\mathrm{N}$ stretching vibrations of aromatic amines, and the band at $1,029.98 \mathrm{~cm}^{-1}$, which is characteristic of glycoside or ether (C-O-C) groups, shifted to $1,056.04 \mathrm{~cm}^{-1}$ in AgNPs. Based on the earlier investigation, we may conclude that functional groups such as hydroxyl, amide, and carbonyl present in the Artemisia argyi leaf extract might be responsible for the 


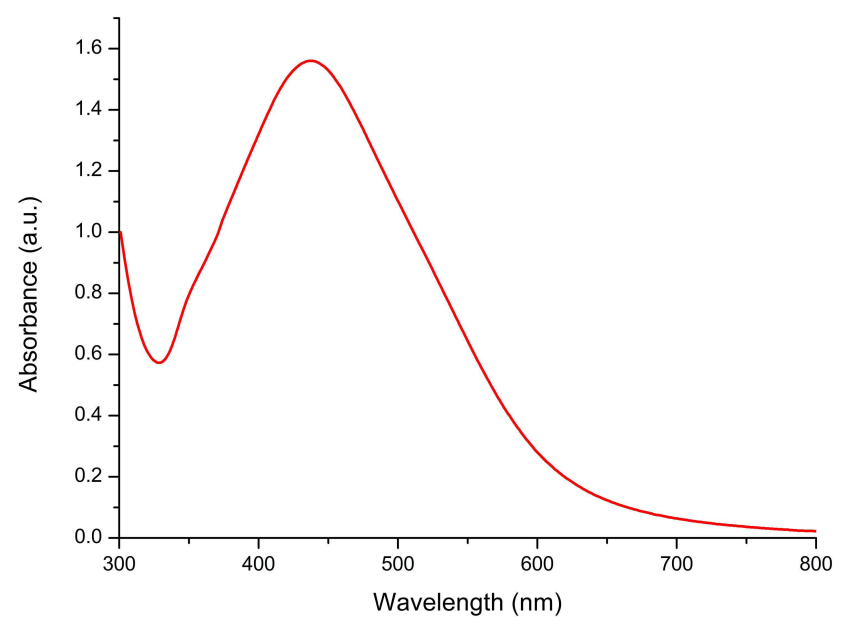

Figure I UV-vis spectroscopy of Artemisia argyi leaf extract-synthesized AgNPs.

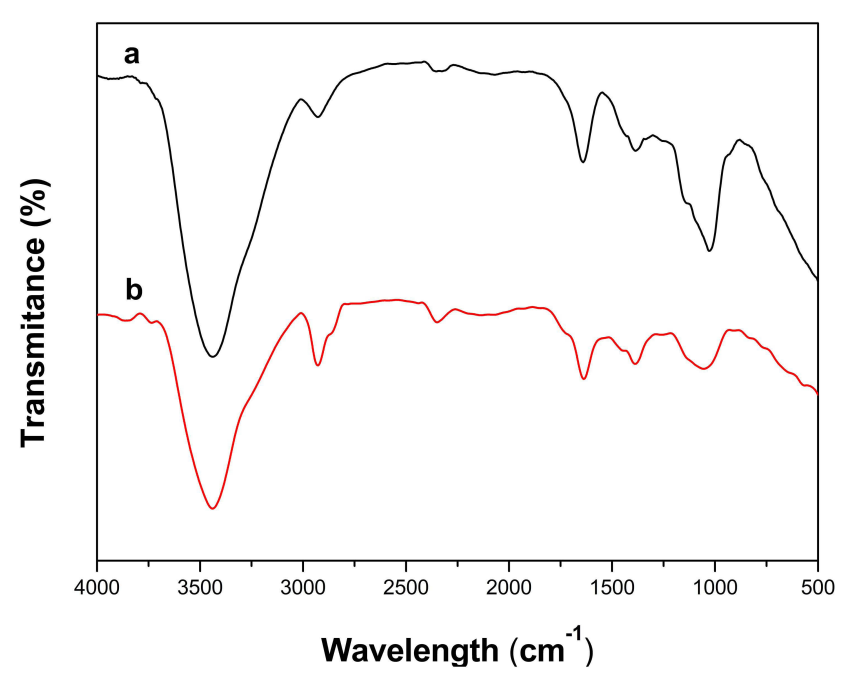

Figure 2 FT-IR spectroscopy of Artemisia argyi leaf extract and Artemisia argyi leaf extract-synthesized AgNPs.

Notes: (A) Artemisia argyi leaf extract, (B) Artemisia argyi leaf extract-synthesized AgNPs.

bioreduction of $\mathrm{Ag}^{+}$to AgNPs. The FTIR spectral results indicate the characteristic functional groups in Artemisia argyi leaf extract as reducing and capping agents for AgNPs.

It was showed that the particle size of Artemisia argyi leaf extract-synthesized AgNPs was about $77.6 \mathrm{~nm}$ (Figure 3), with the variance [P.I.] of 0.295.

\section{The Inhibition Zone Result of AgNPs and Domiphen}

In order to confirm the bacteriostatic properties of synthetic Artemisia argyi leaf extract-synthesized AgNPs and domiphen, we did the inhibition zone test and single-drug susceptibility test. According to Figure 4, compared with the control group, the AgNPs $(60 \mu \mathrm{g} / \mathrm{mL})$ group showed a significantly larger inhibition zone against Staphylococcus aureus (ATCC 6538), Escherichia coli (8099), Acinetobacter baumannii (ATCC 19606) and Candida albicans (ATCC 10231). It indicated that $60 \mu \mathrm{g} /$ $\mathrm{mL}$ AgNPs produced obvious antimicrobial effects against these pathogens. In addition, compared with the control group, the domiphen $(60 \mu \mathrm{g} / \mathrm{mL})$ group presented a larger antimicrobial circle against the above pathogens. It suggested that $60 \mu \mathrm{g} / \mathrm{mL}$ domiphen was effective against the above pathogens. Then, the diameter of the bacteriostatic ring was measured. As shown in Table 1, the ring diameter of Staphylococcus aureus, Escherichia coli, Acinetobacter baumannii and Candida albicans, which was treated with the AgNPs $(60 \mu \mathrm{g} / \mathrm{mL})$ group was $19 \pm 2 \mathrm{~mm}, 16 \pm 1 \mathrm{~mm}$, or $13 \pm 1 \mathrm{~mm}$, correspondingly. In addition, the antimicrobial rings diameters of the domiphen $(60 \mu \mathrm{g} / \mathrm{mL})$ group were $12 \pm 3 \mathrm{~mm}, 10 \pm 3 \mathrm{~mm}$, and $11 \pm 3 \mathrm{~mm}$, respectively. The result indicated that AgNPs and domiphen have good antibacterial effects on the 4 strains.

\section{Single Drug Susceptibility Test}

The MICs of AgNPs and domiphen against Acinetobacter baumannii, Staphylococcus aureus, Escherichia coli and Candida albicans were determined by the microdilution method based on CLSI standards. As shown in Figure 5A, the Acinetobacter baumannii microbial solution was turbid without AgNPs. When the concentration of the AgNPs solution was $2 \mu \mathrm{g} / \mathrm{mL}$ or more, the Acinetobacter baumannii microbial solution was clear. The minimum concentration of AgNPs (2 $\mu \mathrm{g} / \mathrm{mL}$ ) without microbial growth (obviously clear) was the MIC of AgNPs against Acinetobacter baumannii. As shown in Figure 5B-D, the MICs of AgNPs against Staphylococcus aureus, Escherichia coli and Candida albicans were $2 \mu \mathrm{g} / \mathrm{mL}, 2 \mu \mathrm{g} / \mathrm{mL}$ and $4 \mu \mathrm{g} / \mathrm{mL}$, respectively. As shown in Figure 6A-D, the MICs of domiphen against Acinetobacter baumannii, Staphylococcus aureus, Escherichia coli and Candida albicans were $2 \mu \mathrm{g} /$ $\mathrm{mL}, 4 \mu \mathrm{g} / \mathrm{mL}, 8 \mu \mathrm{g} / \mathrm{mL}$, and $4 \mu \mathrm{g} / \mathrm{mL}$, respectively. The results indicated that AgNPs and domiphen can inhibit the growth of pathogens at lower concentrations.

\section{Combined Drug Susceptibility Test}

In order to determine the synergistic antimicrobial ability of Artemisia argyi leaf extract-synthesized AgNPs and domiphen, we did combined drug susceptibility test. The checkerboard microdilution method was used to determine the combined drug sensitivity of AgNPs and domiphen at 


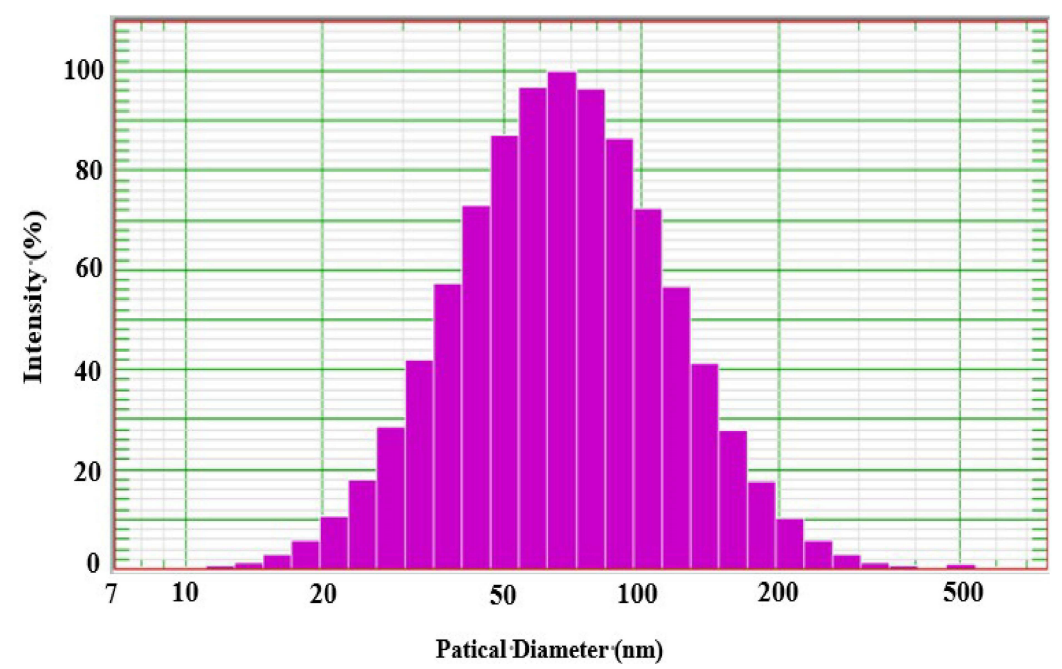

Figure 3 Particle size analysis of Artemisia argyi leaf extract-synthesized AgNPs.

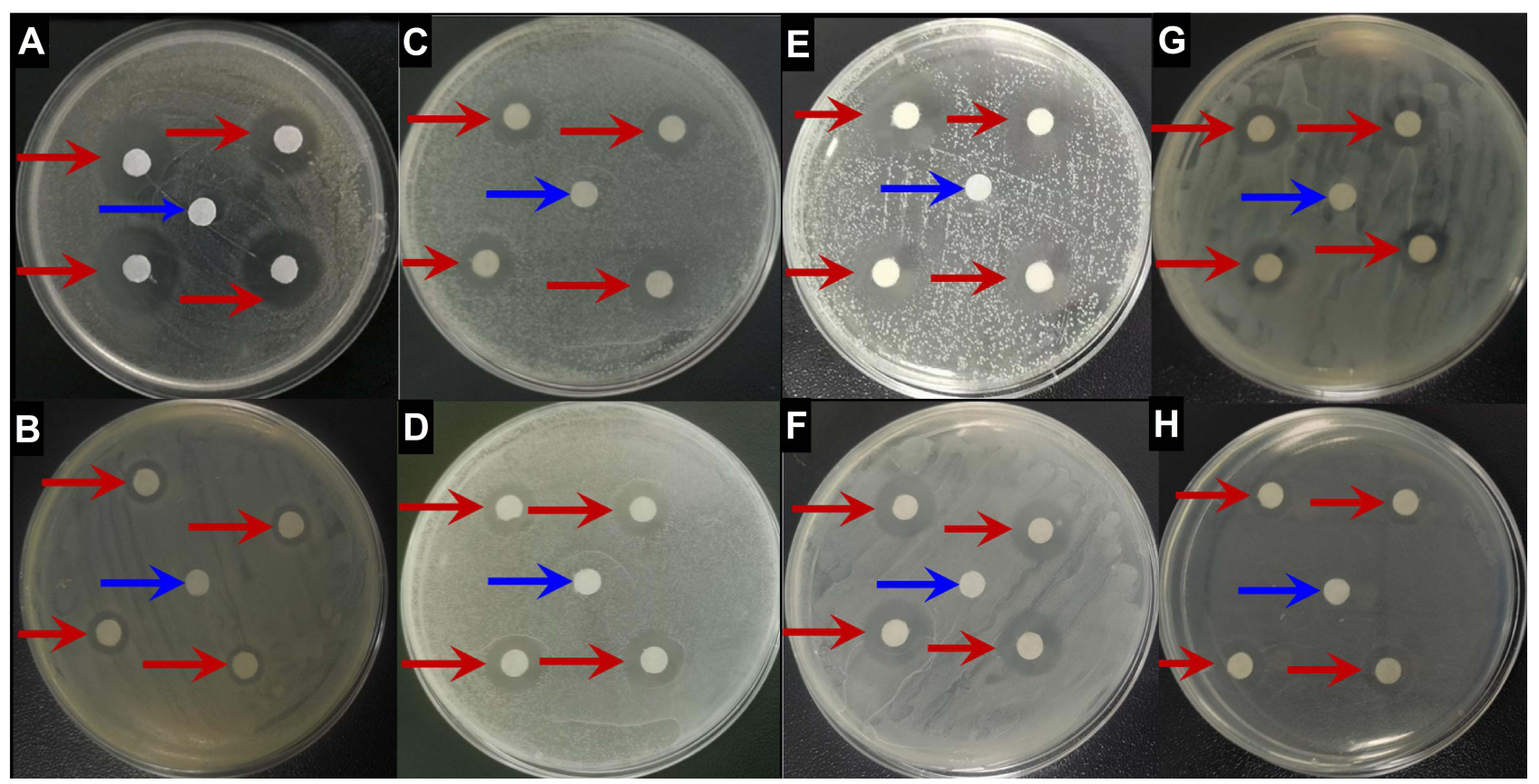

Figure 4 The results of the antimicrobial loop test of the control group and the $60 \mu \mathrm{g} / \mathrm{mL}$ AgNPs and $60 \mu g / \mathrm{mL}$ domiphen.

Notes: (A) AgNPs against Staphylococcus aureus, (C) AgNPs against Echerichia coli, (E) AgNPs against Candida albicans and (G) AgNPs against Acinetobacter baumannii. (B) domiphen against Staphylococcus aureus, (D) domiphen against Echerichia coli, (F) domiphen against Candida albicans and $(\mathbf{H})$ domiphen against Acinetobacter baumannii. The red arrow indicates the $60 \mu \mathrm{g} / \mathrm{mL}$ antimicrobial agent group, and the blue arrow indicates the control group.

different concentrations towards four strains of pathogens. The results of FIC judgement could be expressed as synergistic, additive, antagonistic and irrelevant effects. As shown in Table 2, the combined use of AgNPs and domiphen produced synergistic effects against the above four pathogens (FIC $\leq 0.5)$. The results suggested that the synergistic effects of AgNPs combined with domiphen could enhance the effectiveness of antimicrobial drugs. It could not only reduce the dose of drugs but also reduce the toxicity of drugs.

\section{Minimum Bactericidal Concentration Test}

In order to confirm the bactericidal properties of synthetic Artemisia argyi leaf extract-synthesized AgNPs and domiphen, we did the minimum bactericidal concentration test. As shown in Figure 7A, a large number of Acinetobacter 
Table I Antimicrobial Ring Diameter of AgNPs and Domiphen

\begin{tabular}{|l|c|c|c|c|}
\hline Diameter of Antimicrobial Ring (mm) & Staphylococcus aureus & Escherichia coli & Candida albicans & Acinetobacter baumannii \\
\hline AgNPs & $19 \pm 2$ & $13 \pm 1$ & $16 \pm 2$ & $13 \pm 1$ \\
Domiphen & $10 \pm 1$ & $12 \pm 1$ & $16 \pm 1$ & $12 \pm 1$ \\
\hline
\end{tabular}

baumannii cells grew in the control group. Compared with the control group, the petri dishes treated with $8 \mu \mathrm{g} / \mathrm{mL}$ AgNPs grew aseptic. Therefore, the MBC of AgNPs against Acinetobacter baumannii was $8 \mu \mathrm{g} / \mathrm{mL}$. As shown in Figure 7B-D, the MBC of AgNPs against Staphylococcus aureus, Escherichia coli, and Candida albicans were $32 \mu \mathrm{g} /$ $\mathrm{mL}, 32 \mu \mathrm{g} / \mathrm{mL}$ and $32 \mu \mathrm{g} / \mathrm{mL}$, respectively. As shown in Figure 8A-D, the MBC of domiphen against Acinetobacter baumannii, Staphylococcus aureus, Escherichia coli, and Candida albicans were $8 \mu \mathrm{g} / \mathrm{mL}, 16 \mu \mathrm{g} / \mathrm{mL}, 256 \mu \mathrm{g} / \mathrm{mL}$ and $512 \mu \mathrm{g} / \mathrm{mL}$, respectively. The result suggested that AgNPs have a good bactericidal effect, while the bactericidal effect of domiphen varies with the type of pathogen.

\section{Identification Results of the Ability of Each Pathogen to Form Pathogenic Biofilm}

Meanwhile, the ability of biofilm formation of the four strains was tested. The crystal violet staining was used to test the biofilm-forming ability of the pathogens (Table 3). With respect to the ODc value, Acinetobacter baumannii was a strain with strong membrane forming ability (OD600 $\geq$ 6ODc); Staphylococcus aureus was a strain with strong membrane forming ability $(\mathrm{OD} 600 \geq 6 \mathrm{ODc})$; Escherichia coli was a strain with medium membrane forming ability (4ODc $\leq$ OD600 $\leq 6 \mathrm{ODc})$; and Candida albicans was a medium filmforming ability strain $(4 \mathrm{ODc} \leq \mathrm{OD} 600 \leq 6 \mathrm{ODc})$.

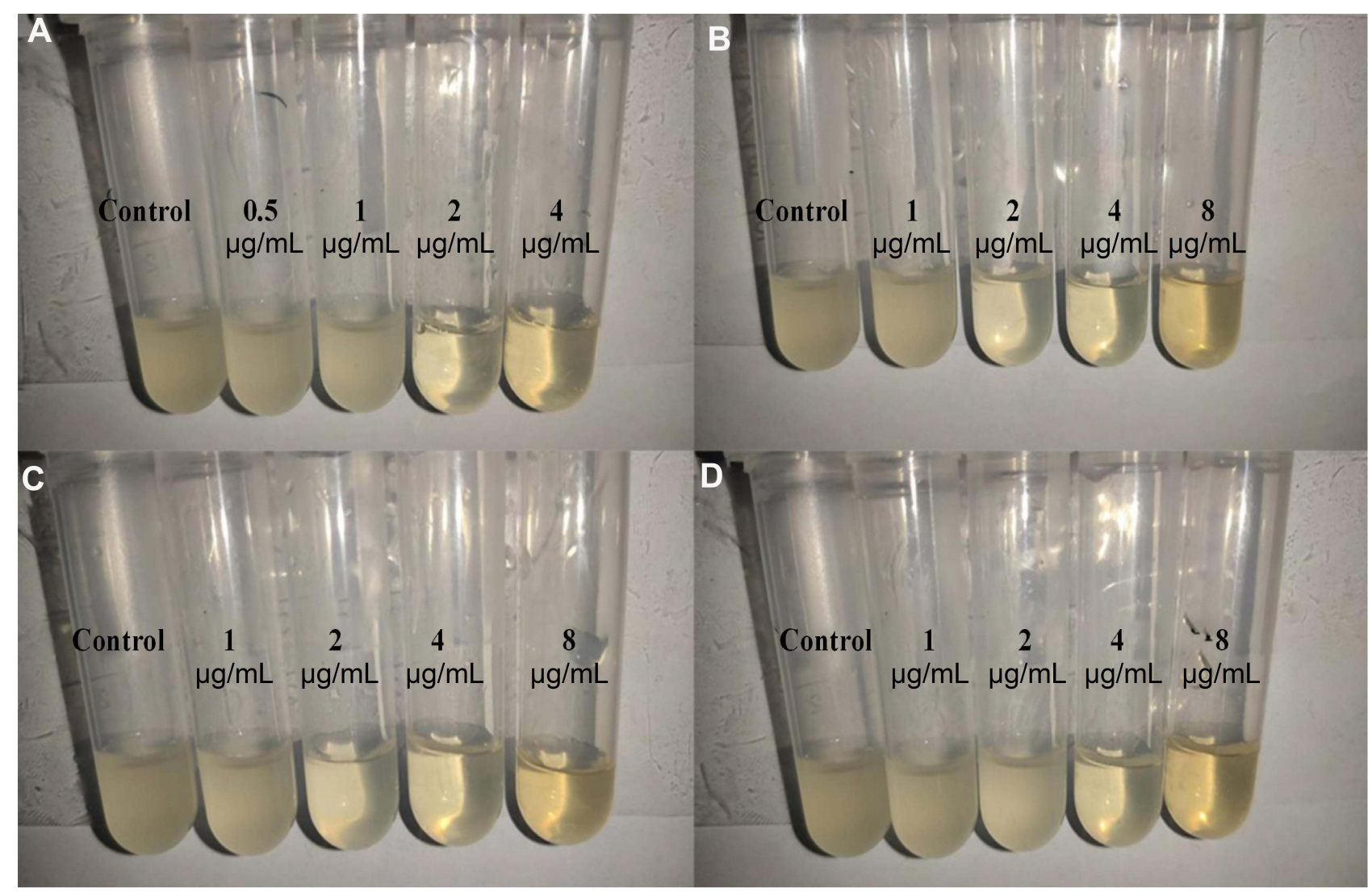

Figure 5 The MIC $(\mu \mathrm{g} / \mathrm{mL})$ test results of the control group and different concentrations of AgNPs group.

Notes: (A) Acinetobacter baumannii, (B) Staphylococcus aureus, (C) Escherichia coli and (D) Candida albicans. The corresponding AgNPs concentration of each centrifuge tube is shown in the figure. 


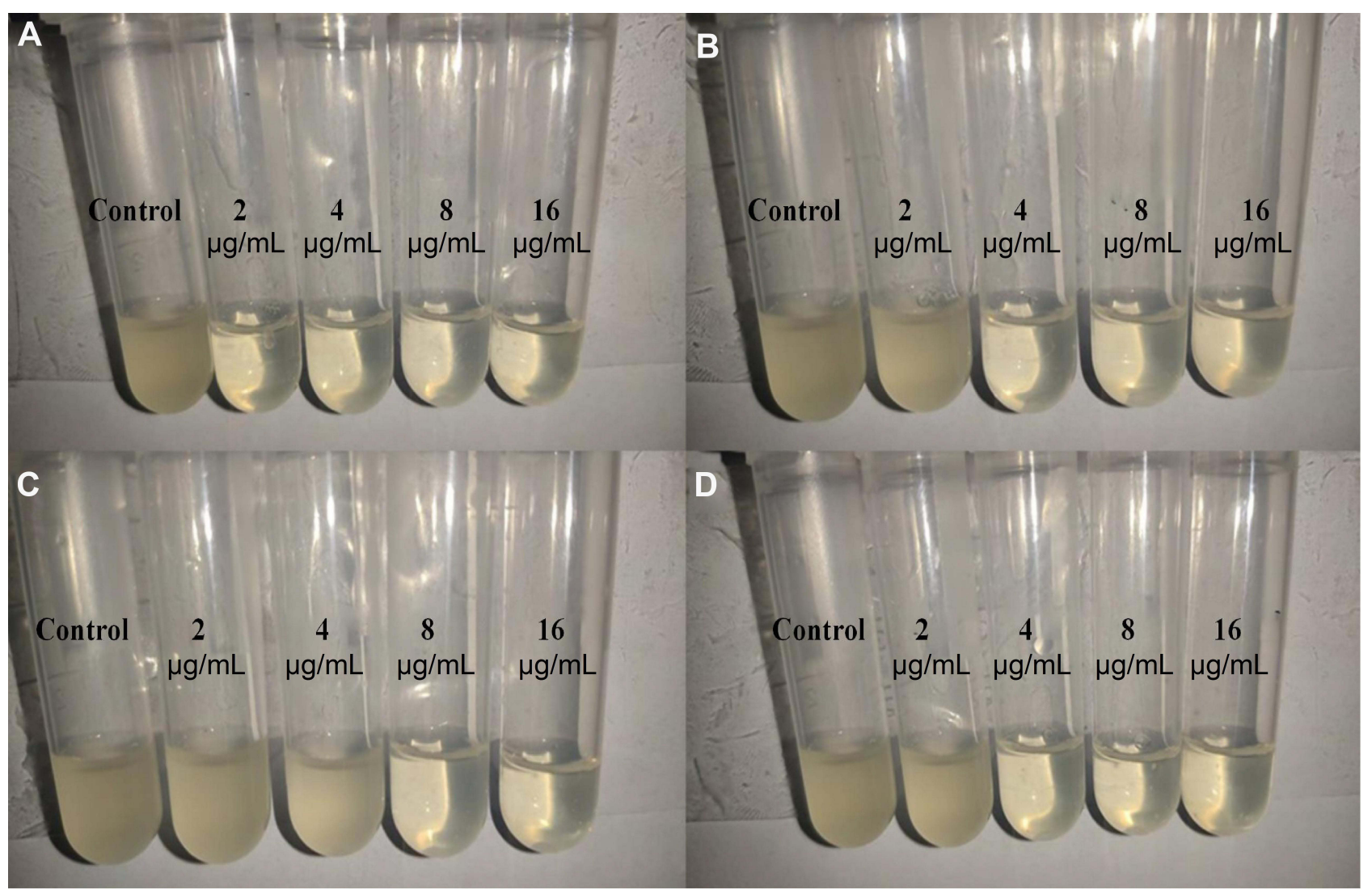

Figure 6 The MIC $(\mu \mathrm{g} / \mathrm{mL})$ test results of the control group and different concentrations of domiphen group.

Notes: (A) Acinetobacter baumannii, (B) Staphylococcus aureus, (C) Escherichia coli and (D) Candida albicans. The corresponding domiphen concentration of each centrifuge tube is shown in the figure.

\section{Pathogenic Biofilm Eradication Concentration Test}

In order to confirm the anti-biofilm abilities of synthetic Artemisia argyi leaf extract-synthesized AgNPs and domiphen, we did the biofilm eradication concentration test. As shown in Figure 9A, compared with the control group, there were no changes in the pathogenic biofilm of the AgNPs group at a concentration of $1 \times$ MIC. What's more, the biofilm of Acinetobacter baumannii cells was reduced by $50 \%$ after treating with $2 \times$ MIC of AgNPs. And the difference was significant $(\mathrm{P}<$
0.01). The $\mathrm{MBEC}_{50}$ (the minimum antimicrobial concentration that eradicates more than $50 \%$ of the pathogenic biofilm biomass) of AgNPs against Acinetobacter baumannii was $2 \times$ MIC. As shown in Figure 9C, E, and $\mathrm{G}$, the $\mathrm{MBEC}_{50}$ of AgNPs against Staphylococcus aureus, Escherichia coli, and Candida albicans were $2 \times$ MIC, $1 / 4 \times$ MIC, and $1 \times$ MIC, respectively. As shown in Figure $9 \mathrm{~B}, \mathrm{D}, \mathrm{F}$ and $\mathrm{H}$, the $\mathrm{MBEC}_{50}$ of domiphen against Acinetobacter baumannii, Staphylococcus aureus, Escherichia coli and Candida albicans were $2 \times$ MIC, $1 / 2 \times$ MIC, $1 \times$ MIC and $1 \times$ MIC, respectively.

Table 2 Drug Susceptibility Test of AgNPs and Domiphen Combined

\begin{tabular}{|l|c|c|c|c|c|}
\hline \multirow{2}{*}{ Strains } & \multicolumn{2}{|c|}{ MIC $(\mu \mathrm{g} / \mathrm{mL})$} & \multicolumn{2}{c|}{ MIC' $(\mu \mathrm{g} / \mathrm{mL})$} & \multirow{2}{*}{ FIC } \\
\cline { 2 - 6 } & AgNPs & Domiphen & AgNPs & Domiphen \\
\hline Acinetobacter baumannii (ATCC19606) & 2 & 2 & $1 / 2$ & $1 / 2$ & 0.5 \\
Staphylococcus aureus (ATCC6538) & 2 & 4 & $1 / 2$ & $1 / 2$ & 0.375 \\
Escherichia coli (8099) & 2 & 8 & $1 / 8$ & 1 & 0.1875 \\
Candida albicans (ATCCI023I) & 4 & 4 & $1 / 4$ & 1 & 0.3125 \\
\hline
\end{tabular}

Abbreviations: MIC, minimum inhibitory concentration; FIC, fractional inhibitory concentration. 


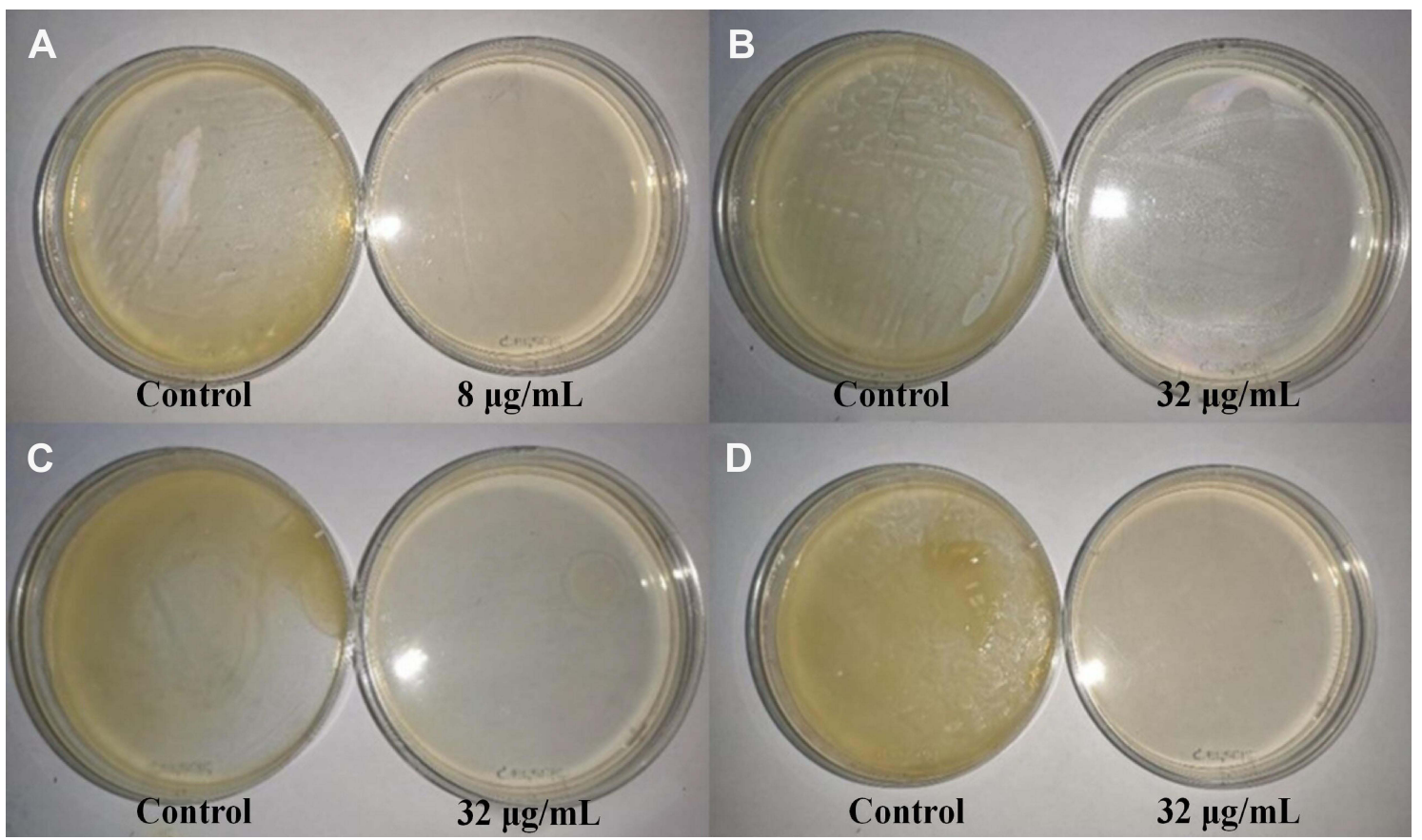

Figure 7 The $M B C(\mu g / m L)$ test results of the control group and the different concentrations of AgNPs group.

Notes: (A) Acinetobacter baumannii, (B) Staphylococcus aureus, (C) Escherichia coli and (D) Candida albicans. The corresponding AgNPs concentration of each petri dish is shown in the figure.
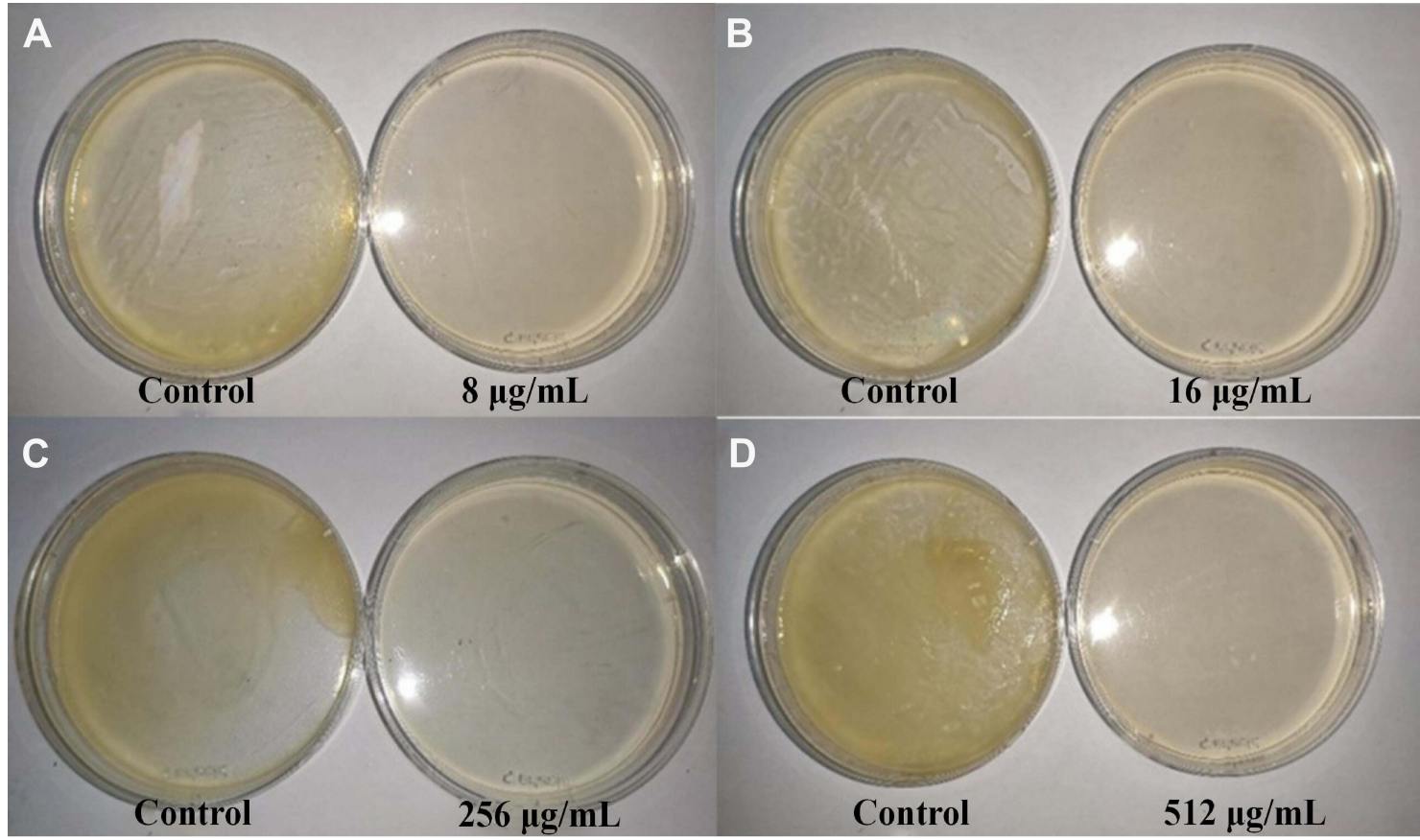

Figure 8 The $M B C(\mu g / m L)$ test results of the control group and different concentrations of domiphen group.

Notes: (A) Acinetobacter baumannii, (B) Staphylococcus aureus, (C) Escherichia coli and (D) Candida albicans. The corresponding domiphen concentration of each petri dish is shown in the figure. 
Table 3 Identification of Strains' Biofilm Forming Ability

\begin{tabular}{|l|c|c|}
\hline Strains & $\mathbf{O D}_{\mathbf{6 0 0}}$ & Identification of Film Forming Ability \\
\hline Control & 0.210 & - \\
Acinetobacter baumannii & 1.396 & Strong \\
Staphylococcus aureus & 2.553 & Strong \\
Escherichia coli & 0.989 & Medium \\
Candida albicans & 0.902 & Medium \\
\hline
\end{tabular}

\section{Combined Drug $\mathrm{MBEC}_{50}$ Test}

In order to determine the synergistic interaction between AgNPs and domiphen on the amount of pathogenic biofilms, the combined drug $\mathrm{MBEC}_{50}$ test was conducted. According to Table 4, after being treated by the combination of AgNPs and domiphen, the biofilms of the above four pathogens have been partially eradicated, especially for Acinetobacter baumannii, Escherichia coli, and Candida albicans. And the combined drugs had a synergistic effect.

\section{Discussion}

There has been a long and complicated struggle for human beings and pathogenic microorganisms. Various diseases caused by pathogens are difficult to treat and inappropriate use of antimicrobial drugs may cause acquired drug resistance, which seriously endangers public health and environmental safety. ${ }^{16}$ The current study found that, after AgNPs or domiphen being used alone, it produced antimicrobial activity against common pathogens (Acinetobacter baumannii, Staphylococcus aureus, Escherichia coli, and Candida albicans). However, when drugs used in combination, they could play synergistic antimicrobial effects. The drug resistance of these above-mentioned strains that formed biofilms were increased. The combined use of AgNPs and domiphen could eradicate of pathogenic biofilms, deactivate common pathogens, and suppress the development of drug resistance. These findings suggested that the combination of AgNPs and domiphen could exert good synergistic effects at low concentrations, which inhibited the growth of pathogens and reduced the use of drugs. The combination of drugs could become a new method to prevent and treat various common pathogens in clinical infection, and provide theoretical evidence for the prevention and treatment of various pathogens.

Acinetobacter baumannii, a gram-negative bacterium, is highly resistant to the antibiotics currently used in clinical practice. The predicament of clinical treatment of Acinetobacter baumannii infection is mainly the lack of lowtoxic and effective antimicrobial drugs. ${ }^{5}$ Staphylococcus aureus, a common food-borne pathogenic microorganism, can produce enterotoxins under appropriate conditions, causing food poisoning and becoming the third largest microbial pathogen. ${ }^{44}$ Candida albicans, a conditional pathogen, when the body's resistance is reduced or the flora becomes imbalanced, can multiply and change its growth form to invade human cells and cause diseases. ${ }^{45}$ Escherichia coli, a conditional pathogen, can cause gastrointestinal infections or local tissue and organ infections in humans and animals. ${ }^{46} \mathrm{In}$ this study, Acinetobacter baumannii (ATCC 19606), Staphylococcus aureus (ATCC 6538), Escherichia coli (8099) and Candida albicans (ATCC 10231) as the representative strains of common pathogens were selected and treated with $60 \mu \mathrm{g} / \mathrm{mL}$ AgNPs and $60 \mu \mathrm{g} / \mathrm{mL}$ domiphen. In order to accurately evaluate the antimicrobial activity of AgNPs or domiphen alone on the experimental strains, the single-drug sensitivity test and the minimum antimicrobials concentration of AgNPs and domiphen against the above-mentioned strains test were performed based on the CLSI standard. The above experimental results show that both AgNPs and domiphen can exert good antimicrobial effects on the experimental strains, but the antimicrobial effect of AgNPs and domiphen on common pathogens needs further verification.

Moreover, the chessboard microdilution method was used to determine the combined drug susceptibility test of AgNPs and domiphen. The results showed that when AgNPs and domiphen were used in combination, they produced synergistic effects against the above four pathogens. This finding suggested that combination medication have significant synergistic antimicrobial effects on common pathogens, enhancing the effectiveness of antimicrobial drugs, and reducing the dosage of each drugs and the toxic effects.

Microbial pathogenic biofilm is a unique life phenomenon of pathogens in order to protect their own existence during the growth process, which can escape the body's immune defense and inactivate the effect of antimicrobial drugs, and often cause chronic infection and prolonged healing. ${ }^{47}$ Studies have shown that the formation of pathogenic biofilms is positively related to the drug resistance of pathogens, and pathogenic biofilms can reduce the sensitivity of pathogens to drugs. ${ }^{6}$ It was 

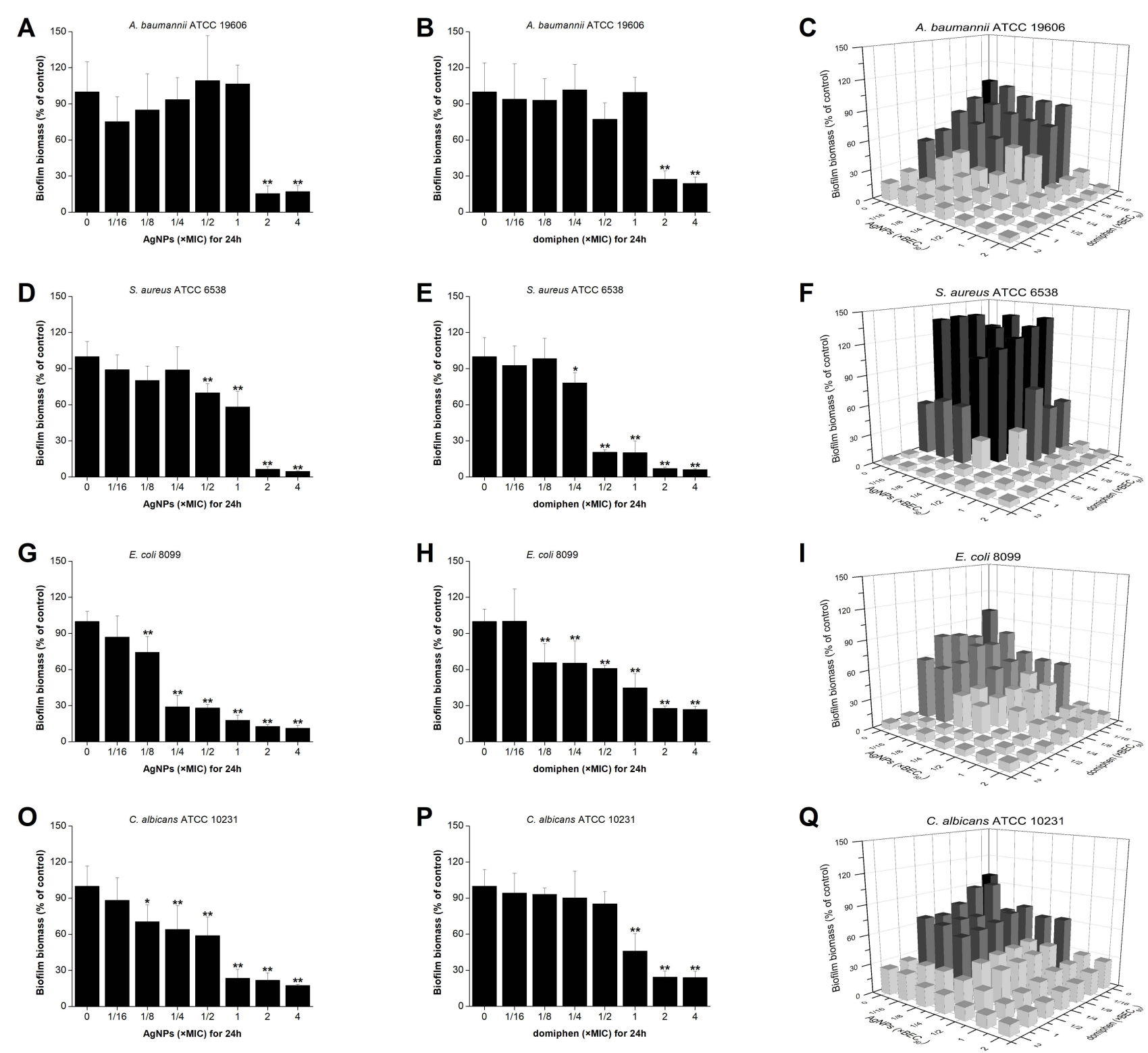

Figure 9 The control group and different concentrations of AgNPs and domiphen group eradicate the pathogenic biofilm. And AgNPs combined with domiphen to eradicate biofilm.

Notes: AgNPs against (A) Acinetobacter baumannii, (D) Staphylococcus aureus, (G) Escherichia coli and (O) Candida albicans. Domiphen against (B) Acinetobacter baumannii, (E) Staphylococcus aureus, (H) Escherichia coli and (P) Candida albicans. AgNPs and domiphen combination against (C) Acinetobacter baumannii, (F) Staphylococcus aureus, (I) Escherichia coli and $(\mathbf{Q})$ Candida albicans Data are represented as mean \pm SD. *Indicates $P<0.05$; **Indicates $P<0.0$ I.

indicated that the drug resistance of the pathogen strains could easily enhance through the formation of bacterial biofilms. $\mathrm{MBEC}_{50}$ referred to the minimum antimicrobial concentration that eradicates more than $50 \%$ of the pathogenic biofilm biomass. Similarly, Kaat De Cremer $^{39}$ verified the use of artemisinin or miconazole alone against the biofilm of Candida albicans SC5314 through the $\mathrm{MBEC}_{50}$ assay. The inhibitory effect was verified by the pathogenic biofilm checkerboard method to have a synergistic interaction when the two drugs were used in combination. In addition, domiphen and miconazole could play synergistic effects against drugresistant Candida ${ }^{40}$ In order to determine the synergistic effects of AgNPs and domiphen on the biomass of pathogenic biofilms, the $\mathrm{MBEC}_{50}$ test was conducted. It showed that, after AgNPs and domiphen being used in combination, they produced synergistic inhibitory effects on the eradicating biofilms of Acinetobacter baumannii (FIC $=0.1875$ ), Staphylococcus aureus $(\mathrm{FIC}=0.5)$, Escherichia coli $(\mathrm{FIC}=0.1875)$, and Candida albicans $(\mathrm{FIC}=0.3125$ ). This finding indicated that the combination of AgNPs and domiphen could exert 
Table 4 AgNPs and Domiphen Eradicate the Pathogenic Biofilms

\begin{tabular}{|l|c|c|c|c|c|}
\hline \multirow{2}{*}{ Strains } & \multicolumn{2}{|c|}{ MBEC $_{\mathbf{5 0}}(\mu \mathrm{g} / \mathrm{mL})$} & \multicolumn{2}{c|}{ MBEC' ${ }_{\mathbf{5 0}}(\mu \mathrm{g} / \mathrm{mL})$} & \multirow{2}{*}{ FIC } \\
\cline { 2 - 6 } & AgNPs & Domiphen & AgNPs & Domiphen \\
\hline Acinetobacter baumannii (ATCC19606) & 4 & 4 & $1 / 4$ & $1 / 2$ & 0.1875 \\
Staphylococcus aureus (ATCC6538) & 4 & 2 & $\mathrm{I}$ & $1 / 2$ & 0.5 \\
Escherichia coli (8099) & $1 / 2$ & 8 & $\mathrm{I} / 16$ & $1 / 2$ & 0.1875 \\
Candida albicans (ATCCI023I) & 4 & 4 & $\mathrm{I}$ & $1 / 4$ & 0.3125 \\
\hline
\end{tabular}

Abbreviations: $\mathrm{MBEC}_{50}$, the minimum antimicrobial concentration that eradicates more than $50 \%$ of the pathogenic biofilm biomass; FIC, fractional inhibitory concentration.

antimicrobial synergistic effects by eradicating the biomass of pathogenic biofilms. We boldly speculate that as a surfactant, domiphen disperses the biofilm matrix and increases the permeability of $\mathrm{AgNPs},{ }^{48}$ thereby improving the bactericidal effect of AgNPs and achieving a synergistic antibacterial effect.

In summary, this study verified that the antimicrobial activity of AgNPs or domiphen being used alone. Furthermore, the combined use of AgNPs and domiphen produced synergistic antimicrobial effects, which may be associated with reducing biomass of pathogenic biofilms.

\section{Conclusion}

1. Artemisia argyi leaf extract-synthesized AgNPs and domiphen alone had antimicrobial activity against Acinetobacter baumannii (ATCC 19606), Staphylococcus aureus (ATCC 6538), Escherichia coli (8099) and Candida albicans (ATCC 10231).

2. The combination of Artemisia argyi leaf extractsynthesized AgNPs and domiphen has synergistic antimicrobial effects to reduce the dosage of each antimicrobial drugs.

3. Artemisia argyi leaf extract-synthesized AgNPs and domiphen have synergistic anti-biofilm effects.

\section{Abbreviations}

AgNPs, silver nanoparticles; MIC, minimum inhibitory concentration; FIC, fractional inhibitory concentration; $\mathrm{MBC}$, minimum bactericidal concentration; $\mathrm{MBEC}_{50}$, the minimum antimicrobial concentration that eradicates more than $50 \%$ of the pathogenic biofilm biomass.

\section{Funding}

This study was supported by 2020 Quality Cultivation Project of the School of Life Sciences, 2021 Higher Education Reform Research Project of School of Life Sciences (2021-1) and Key Projects of Jiangsu
University Student Innovation and Entrepreneurship Training Program (202010313002Z; The public notice number of Xuzhou Medical University: 202151). Xuzhou Medical University. Sponsor had no involvement in any of the stages from study design to submission of the manuscript for publication.

\section{Disclosure}

The authors report a patent CN112471174B licensed to Ruolin $\mathrm{Xu}$, Longhao Hu, Xi Yang, Jing Yin, Xuan Rong, Xinlei Huang, Yipeng Pang, Yi Liu. No other competing interests exist.

\section{References}

1. Brown CA, Hu L, Sun Z, et al. Antagonism between substitutions in $\beta$ lactamase explains a path not taken in the evolution of bacterial drug resistance. J Biol Chem. 2020;295(21):7376-7390. doi:10.1074/jbc. RA119.012489

2. Pagès JM. Transports des antibiotiques et perméabilité membranaire: nouvelles perspectives afin de combattre la résistance bactérienne [Antibiotic transport and membrane permeability: new insights to fight bacterial resistance]. Biol Aujourdhui. 2017;211(2):149-154. French. doi: $10.1051 / \mathrm{jbio} / 2017020$

3. Varela MF, Stephen J, Lekshmi M, et al. Bacterial resistance to antimicrobial agents. Antibiotics. 2021;10(5):593. doi:10.3390/ antibiotics 10050593

4. Fleeman RM, Debevec G, Antonen K, et al. Identification of a novel polyamine scaffold with potent efflux pump inhibition activity toward multi-drug resistant bacterial pathogens. Front Microbiol. 2018;9:1301. doi:10.3389/fmicb.2018.01301

5. Abbott I, Cerqueira GM, Bhuiyan S, Peleg AY. Carbapenem resistance in Acinetobacter baumannii: laboratory challenges, mechanistic insights and therapeutic strategies. Expert Rev Anti Infect Ther. 2013;11(4):395-409. doi:10.1586/eri.13.21

6. Høiby N, Bjarnsholt T, Givskov M, Molin S, Ciofu O. Antibiotic resistance of bacterial biofilms. Int J Antimicrob Agents. 2010;35 (4):322-332. doi:10.1016/j.ijantimicag.2009.12.011

7. Chandra J, Kuhn DM, Mukherjee PK, Hoyer LL, McCormick T, Ghannoum MA. Biofilm formation by the fungal pathogen Candida albicans: development, architecture, and drug resistance. $J$ Bacteriol. 2001;183(18):5385-5394. doi:10.1128/JB.183.18.5385-5394.2001

8. Karaoglan I, Zer Y, Bosnak VK, Mete AO, Namiduru M. In vitro synergistic activity of colistin with tigecycline or $\beta$-lactam antibiotic/ $\beta$ lactamase inhibitor combinations against carbapenem-resistant Acinetobacter baumannii. J Int Med Res. 2013;41(6):1830-1837. doi: $10.1177 / 0300060513496172$ 
9. Hagihara M, Housman ST, Nicolau DP, Kuti JL. In vitro pharmacodynamics of polymyxin B and tigecycline alone and in combination against carbapenem-resistant Acinetobacter baumannii. Antimicrob Agents Chemother. 2014;58(2):874-879. doi:10.1128/AAC.01624-13

10. Pollini S, Brunetti J, Sennati S, et al. Synergistic activity profile of an antimicrobial peptide against multidrug-resistant and extensively drug-resistant strains of Gram-negative bacterial pathogens. J Pept Sci. 2017;23(4):329-333. doi:10.1002/psc.2978

11. Chen X, Schluesener HJ. Nanosilver: a nanoproduct in medical application. Toxicol Lett. 2008;176(1):1-12. doi:10.1016/j. toxlet.2007.10.004

12. Ullah Khan S, Saleh TA, Wahab A, et al. Nanosilver: new ageless and versatile biomedical therapeutic scaffold. Int $J$ Nanomedicine. 2018;13:733-762. doi:10.2147/IJN.S153167

13. Lewinski N, Colvin V, Drezek R. Cytotoxicity of nanoparticles. Small. 2008;4(1):26-49. doi:10.1002/smll.200700595

14. Prabhu S, Poulose EK. Silver nanoparticles: mechanism of antimicrobial action, synthesis, medical applications, and toxicity effects. Int Nano Lett. 2012;2(1):32. doi:10.1186/2228-5326-2-32

15. Li WR, Xie XB, Shi QS, Duan SS, Ouyang YS, Chen YB. Antibacterial effect of silver nanoparticles on Staphylococcus aureus. Biometals. 2011;24(1):135-141. doi:10.1007/s10534-010-9381-6

16. Fumagalli L, Regazzoni LG, Straniero V, et al. Stressed degradation studies of domiphen bromide by LC-ESI-MS/MS identify a novel promising antimicrobial agent. $J$ Pharm Biomed Anal. 2018;159:224-228. doi:10.1016/j.jpba.2018.06.055

17. Xu L, Wang YY, Huang J, Chen CY, Wang ZX, Xie H. Silver nanoparticles: synthesis, medical applications and biosafety. Theranostics. 2020;10(20):8996-9031. doi:10.7150/thno.45413

18. Quintero-Quiroz C, Acevedo N, Zapata-Giraldo J, et al. Optimization of silver nanoparticle synthesis by chemical reduction and evaluation of its antimicrobial and toxic activity. Biomater Res. 2019;23 (1):23-27. doi:10.1186/s40824-019-0173-y

19. Bhangi BK, Ray SK. Nano silver chloride and alginate incorporated composite copolymer adsorbent for adsorption of a synthetic dye from water in a fixed bed column and its photocatalytic reduction. Int J Biol Macromol. 2020;144:801-812. doi:10.1016/j.ijbiomac.2019.09.070

20. Sritong N, Chumsook S, Siri S. Light emitting diode irradiation induced shape conversion of DNA-capped silver nanoparticles and their antioxidant and antibacterial activities. Artif Cells Nanomed Biotechnol. 2018;46 (Suppl 1):S955-S963. doi:10.1080/21691401.2018.1439841

21. Khan MJ, Kumari S, Shameli K, Selamat J, Sazili AQ. Green synthesis and characterization of pullulan mediated silver nanoparticles through ultraviolet irradiation. Materials. 2019;12(15):2382. doi:10.3390/ma12152382

22. Ran P, Jiang L, Li X, Li B, Zuo P, Lu Y. Femtosecond photon-mediated plasma enhances photosynthesis of plasmonic nanostructures and their SERS applications. Small. 2019;15(11): e1804899. doi:10.1002/smll.201804899

23. Jiang HS, Yin L, Ren NN, et al. The effect of chronic silver nanoparticles on aquatic system in microcosms. Environ Pollut. 2017;223:395-402. doi:10.1016/j.envpol.2017.01.036

24. Zeng KW, Wang S, Dong X, Jiang Y, Tu PF. Sesquiterpene dimer (DSF-52) from Artemisia argyi inhibits microglia-mediated neuroinflammation via suppression of NF- $\mathrm{B}, \mathrm{JNK} / \mathrm{p} 38$ MAPKs and Jak2/ Stat3 signaling pathways. Phytomedicine. 2014;21(3):298-306. doi:10.1016/j.phymed.2013.08.016

25. Kang JY, Lee DS, Park SK, et al. Cognitive function of Artemisia argyi H. Fermented by Monascus purpureus under TMT-induced learning and memory deficits in ICR mice. Evid Based Complement Alternat Med. 2017;2017:5809370. doi:10.1155/2017/5809370

26. Zhang XW, Wang S, Tu PF, Zeng KW. Sesquiterpene lactone from Artemisia argyi induces gastric carcinoma cell apoptosis via activating NADPH oxidase/reactive oxygen species/mitochondrial pathway. Eur J Pharmacol. 2018;837:164-170. doi:10.1016/j.ejphar.20 18.07.053
27. Ghazali SZ, Mohamed Noor NR, Mustaffa KMF. Anti-plasmodial activity of aqueous neem leaf extract mediated green synthesis-based silver nitrate nanoparticles. Prep Biochem Biotechnol. 2021:1-9. doi:10.1080/10826068.2021.1913602

28. Irshad S, Mannan A, Mirza B. Antimalarial activity of three Pakistani medicinal plants. Pak J Pharm Sci. 2011;24(4):589-591.

29. Xiao-Yan L, Yuan Z, Long-Bo Z, et al. [Research progress on chemical constituents from Artemisiae Argyi Folium and their pharmacological activities and quality control]. Zhongguo Zhong Yao Za Zhi. 2020;45(17):4017-4030. Chinese.

30. Xiao JQ, Liu WY, Sun HP, et al. Bioactivity-based analysis and chemical characterization of hypoglycemic and antioxidant components from Artemisia argyi. Bioorg Chem. 2019;92:103268. doi:10.1016/j.bioorg.2019.103268

31. Li S, Zhou S, Yang W, Meng D. Gastro-protective effect of edible plant Artemisia argyi in ethanol-induced rats via normalizing inflammatory responses and oxidative stress. $J$ Ethnopharmacol. 2018;214:207-217. doi:10.1016/j.jep.2017.12.023

32. Ali M, Abbasi BH. Light-induced fluctuations in biomass accumulation, secondary metabolites production and antioxidant activity in cell suspension cultures of Artemisia absinthium L. J Photochem Photobiol B. 2014;140:223-227. doi:10.1016/j.jphotobiol.2014.08.008

33. Ali M, Abbasi BH. Thidiazuron-induced changes in biomass parameters, total phenolic content, and antioxidant activity in callus cultures of Artemisia absinthium L. Appl Biochem Biotechnol. 2014;172(5):2363-2376. doi:10.1007/s12010-013-0663-7

34. Ali M, Abbasi BH. Production of commercially important secondary metabolites and antioxidant activity in cell suspension cultures of Artemisia absinthium L. Ind Crops Prod. 2013;49:400-406. doi:10.1016/j.indcrop.2013.05.033

35. Lee Y-J, Thiruvengadam M, Chung I-M, Nagella P. Polyphenol composition and antioxidant activity from the vegetable plant Artemisia absinthium L. Aust J Crop Sci. 2013;7(12):1921-1926.

36. Mith H, Duré R, Delcenserie V, Zhiri A, Daube G, Clinquart A. Antimicrobial activities of commercial essential oils and their components against food-borne pathogens and food spoilage bacteria. Food Sci Nutr. 2014;2(4):403-416. doi:10.1002/fsn3.116

37. Mwitari PG, Ayeka PA, Ondicho J, Matu EN, Bii CC. Antimicrobial activity and probable mechanisms of action of medicinal plants of Kenya: Withania somnifera, Warburgia ugandensis, Prunus africana and Plectranthus barbatus. PLoS One. 2013;8(6):e65619. doi:10.1371/journal.pone.0065619

38. Elekhnawy EA, Sonbol FI, Elbanna TE, et al. Evaluation of the impact of adaptation of Klebsiella pneumoniae clinical isolates to benzalkonium chloride on biofilm formation. Egypt J Med Hum Genet. 2021;22(1):51. doi:10.1186/s43042-021-00170-z

39. De Cremer K, Lanckacker E, Cools TL, et al. Artemisinins, new miconazole potentiators resulting in increased activity against Candida albicans biofilms. Antimicrob Agents Chemother. 2015;59 (1):421-426. doi:10.1128/AAC.04229-14

40. Tits J, Cools F, De Cremer K, et al. Combination of Miconazole and Domiphen Bromide is fungicidal against biofilms of resistant Candida spp. Antimicrob Agents Chemother. 2020;64(10):e0129620. doi:10.1128/AAC.01296-20

41. Dauthal P, Mukhopadhyay M. In-vitro free radical scavenging activity of biosynthesized gold and silver nanoparticles using Prunus armeniaca (apricot) fruit extract. J Nanopart Res. 2013;15(1):1366. doi:10.1007/s11051-012-1366-7

42. Noruzi M, Zare D, Davoodi D. A rapid biosynthesis route for the preparation of gold nanoparticles by aqueous extract of cypress leaves at room temperature. Spectrochim Acta A Mol Biomol Spectrosc. 2012;94:84-88. doi:10.1016/j.saa.2012.03.041

43. Arthanari S, Mani G, Jayabalan J, Hyun TJ. Biosynthesis of silver nanoparticles using Cassia tora leaf extract and its antioxidant and antimicrobial activities. $J$ Ind Eng Chem. 2015;28:277-281. doi:10.1016/j.jiec.2015.03.003 
44. Voss A, Doebbeling BN. The worldwide prevalence of methicillin-resistant Staphylococcus aureus. Int $J$ Antimicrob Agents. 1995;5(2):101-106. doi:10.1016/0924-8579(94)00036-T

45. Cowen LE, Sanglard D, Calabrese D, Sirjusingh C, Anderson JB, Kohn LM. Evolution of drug resistance in experimental populations of Candida albicans. $J$ Bacteriol. 2000;182(6):1515-1522. doi:10.1128/JB.182.6.1515-1522.2000

46. Fei S, Min J, Wang Y. Analysis of pathogenic bacteria distribution and Escherichia coli drug resistance in urinary tract infection. Int J Lab Med. 2013;34:3031-3032.
47. Sardi JCO, Scorzoni L, Bernardi T, Fusco-Almeida AM, Mendes Giannini MJS. Candida species: current epidemiology, pathogenicity, biofilm formation, natural antifungal products and new therapeutic options. J Med Microbiol. 2013;62(Pt 1):10-24. doi:10.1099/ jmm.0.045054-0

48. Li P, Chen X, Shen Y, et al. Mucus penetration enhanced lipid polymer nanoparticles improve the eradication rate of Helicobacter pylori biofilm. J Control Release. 2019;300:52-63. doi:10.1016/j. jconrel.2019.02.039

\section{Publish your work in this journal}

The International Journal of Nanomedicine is an international, peerreviewed journal focusing on the application of nanotechnology in diagnostics, therapeutics, and drug delivery systems throughout the biomedical field. This journal is indexed on PubMed Central, MedLine, CAS, SciSearch ${ }^{\mathbb{R}}$, Current Contents ${ }^{\mathbb{R}} /$ Clinical Medicine, $^{-}$
Journal Citation Reports/Science Edition, EMBase, Scopus and the Elsevier Bibliographic databases. The manuscript management system is completely online and includes a very quick and fair peer-review system, which is all easy to use. Visit http://www.dovepress.com/ testimonials.php to read real quotes from published authors. 